\title{
Marie Curie Fellowships
}

Results from 16 June 1997 deadline

\begin{tabular}{lcccr} 
Type of fellowship & & & & \\
& Financed & Rejected & In Reserve & Total \\
\hline Postgraduate & 12 & 115 & 3 & 130 \\
\hline Postdoctoral & 65 & 166 & 14 & 245 \\
\hline Experienced Scientist & 3 & 1 & 0 & 4 \\
Return Grant & 3 & 1 & 0 & 4 \\
\hline Total & $\mathbf{8 3}$ & $\mathbf{2 8 3}$ & $\mathbf{1 7}$ & $\mathbf{3 8 3}$
\end{tabular}

Up to last summer's deadline for Marie Curie Fellowshipsm - the last deadline before Framework 5 for the grants which enbable researchers to work in another European country other than their own a total of 383 proposals were received from physicists. They were evaluated by a panel of 45 experts, of which Jocelyn Bell-

Burnell, of the Open University in the UK, is currently president. The guidelines used by the referees are openly available at the European Union's Website, at $w w w$. cordis.lu/tmr/home.html. sion was, according to DG12, the European Commission department that handles science funding, 3 months and 3 weeks. Science ministers last November agreed on strict time limits for Framework 5, and also agreed to place applications in the hands of managers, rather than Committees, in the future.
The delay between deadline and deci-

Results by country

\begin{tabular}{lcc} 
Austria & $\begin{array}{c}\text { Nationality } \\
\text { of Candidate }\end{array}$ & $\begin{array}{c}\text { Host } \\
\text { Lab. }\end{array}$ \\
\hline Belgium & 1 & 1 \\
\hline Germany & 1 & 1 \\
\hline Denmark & 24 & 12 \\
\hline Spain & 8 & 3 \\
\hline Finland & - & 5 \\
\hline France & 18 & 2 \\
\hline United Kingdom & 7 & 20 \\
\hline Greece & 3 & 17 \\
\hline Ireland & 1 & 3 \\
\hline Iceland & 1 & - \\
\hline Italy & 11 & - \\
\hline The Netherlands & 4 & 9 \\
\hline Portugal & 1 & 7 \\
\hline Sweden & 1 & - \\
\hline Switzerland & - & 2 \\
\hline Total & 83 & 1 \\
\hline
\end{tabular}

Results by discipline

\section{Post Doctoral Position for Planetary Sciences at the University of Bern/Switzerland}

The Department for Mass Spectrometry and Space Research of the Physikalisches Institut at the University of Bern, Switzerland, invites applications for a Research Associate appointment.

The successful applicant is expected to be a recent PhD recipient and have a demonstrated expertise in planetary sciences. Fields of particular interests to the department include - but are not limited to the theory of formation and/or evolution of planetary systems, of small bodies in the solar system (asteroids, comets) and the physics of impacts. He/she should be able to carry out independent research as well as to participate actively in the other activities of the department such as supervision of undergraduate/graduate students and administration.

Salary is according to qualifications and conditions stipulated by the University of Bern. The appointment will be for a period of two years.

Applications including a curriculum vitae, a list of publications, a description of current and planned research activities, and the name and mailing/e-mail address of three references should be sent before February 1, 1998, to

Prof. W. Benz,

Physikalisches Institut, University of Bern,

Sidlerstrasse 5, CH-3012 Bern, Switzerland.

For further information call W. Benz +41316314403 (direct) or +41316314404 (secretary). E-mail:willy.benz@phim.unibe.ch 